\title{
PROBLEM SOLVING APPLIED TO LANGUAGE GENERATION
}

\author{
Douglas E. Appelt \\ Sianford University. Slanford, Califormia \\ SRI International Mtenlo Park, California
}

\begin{abstract}
This research was supported at SRI International by the Defense Advanced Research Projects Agency under cuntrac No0039-79-C-0118 with the Naval Electronic Systems Conmand The views and conclusions contained in this documient are those of the author and should not be interpreter as representative of the official policies either expressed or implied. of the Defense idvanced Research Projects Agency, or the U. S. Govenument. The author is grateful to Burbara Girosz, Gary Hendrix and Terry Winograd for conments on an earlier draft of this paper.
\end{abstract}

\section{Introduction}

Previous approaches to designing language understanding systems have considered language generation to be the activity of a highly specialized linguistic facilicy that is largely independent of other cognitive capabilities. All the requisite knowledge for generation is embodicd in a "generation module" which, with appropriate modifications to the lexicon, is transportable between different domains and applications. Application programs constrict "messages" in some interıal representation, sucll as first order predicate calculus or semantic networks, and hand them to the generation module to be iransiated into latural langtuge. The application program decides what to say: the generation module decides how to say it.

In cuntrast with this previous work, this paper proposes an approach to designing a language generation system that builds on the vicw of language as action which has evolved from speceh act theory (sce Nustin [2] and Scarie [11]). According to this vicw, linguistic actions are actions planned to satisfy particular goals of the speaker, similar to other actions like moving and looking. Language production is integrated with a spcaker's problem solving processes. This appronch is founded on the hypothesis that planning and performing linguistic actions is an activity that is not substantially different from planning and performing other kinds of physical actions. The process of producing an utterance involves planning actions to satisfy a number of differene kinds of goals, and then efficiently coordinating the actions that satisfy these goals. In the resulting framework, there is no distinction between deciding what to say and deciding how to say it.

This research has procecded through a simuitaneous, integrated effort in two arcas. The first area of rescarch is the theorctical problem of identifying the goals and actions that occur in human communication and then characterizing them in planning terms. The second is the more applied task of developing machine-based planning methods that are adcquate to form plans based on the characterization developed as part of the work in the first ares. The eventual goal is to merge the results of the two areas of effor into a planning system that is capable of producing English sentences.

Rather than relying on a specialized generation module, language generation is performed by a gencral problcm-solving system that has 3 great deal of knowledge about language. $\Lambda$ planning system, named KAMP (Knowledge and Modalities Planncr), is currently under development that can take a high-level goal and plan to achicve it through boch linguistic and non-linguistic actions. Means for satisfying multple goals can be integrated into a single utterancc.

This paper examines the goals that arise in a dialog, and what actions satisfy those goals. It then discusses an example of a sentence which satisfies severai goals simultaneously, and how KAMP will be able to produce this and similar utterances. This system represents an extension to Cohen's work on planning speceh acts [3]. However, unlike Cohen's system which plans actions on the level of informing and requesting, but does not actually generace natural language sentences, KAiV applics general problem-solving techniques to the entire language gencration process, including the construction of the utterance.

\section{Goals and $\Lambda$ ctions used in Task Oriented Dialogues}

The participants in a dialogue have four different major types of goals which may be satisfied, either directly or indirectly, through utterances. Physical goais, involve the physical state of the world. The physical state can only be aitered by actions that have pliysical effects, and so speech acts do not serve directly to achicre ulese goals. But since physical goals give rise to other types of goals as subgoals, which may in turn be satisfied by spcech acts, they arc important to a language planning systein. Goals that bear directy on the utterances themsclves are knowledge state goals discourse goals and social goais.

Any goal of a speaker can fit into one of these four calcgorics. However, cach category has many sub-categorics, with the goals in cach sub-catcgory being satisficd by actions related to but different from those satisfying the goals of other sub-catcgorics. Delincating the primary catcgurizations of goals and actions is one objective of this rescarch.

Knowledge state goals involve changes in the belicfs and wants held by the speaker or the hearer. They may be satisficd by several different kinds of actions. Physical actions affect knowledge, since as a miniunum the agent knows he has performed the action. There are also actions that affect only knowledge and do not change the state of the world - for example. rcading. looking and speech acts. Specch acts are a special case of knowledge-producing actions because they do not produce knowledge directly, like looking at a clock. Instead, the cffects of specch acts manifest themselves through the recognicion of intention. The effect of a spech act. according to Searle, is that the hearcr recognizes the speaker's intention to perform the act. The hearer then knows which speech act has been performed, and because of rules governing the communication processes, such as the Gricean maxims [4], the hearer makes inferences about the speaker's beliefs. These inferences all affect the hearer's uwn beliefs.

Discourse goals are goals that involve maintaining or changing the state of the discourse. For example, a goal of focusing on a different concept is a type of discourse goal $[5,9,12]$. The utterance Take Jolin, for instance scrves to muve the participants' focusing from a gencral subject to a specific examplc. Utterances of this nature seem to be explainable only in terms of the effects they have, and not in tcrms of a formal specification of their propositional content.

Concept activation goals are a particular catcgory of discourse goais. These are goals of bringing a concept of some object. statc, or event into the hearer's immediate conciousness so that he understands its rolc in the utternnce. Concept activation is a general gual that subsumes different kinds of speaker reference. It is a low-ievel goal that is not considered until the later stages of the planning process, but it is interesting because of the large number of interactions between it and higher-icyel goals and the large number of options available by which concept activations can be performed. 
Social gonls atso play an important par in the planning of utterances. These guals are fundamentilly different from ocher goals in that frequently they are not effects to be aclieved $\$$ ) much as constraints on the possible behavior that is acceptabic in a given situation. Social goals relate to politeness, and are reflected in the surface form and content of the utterance. However, there is no simple "formula" that one can follow to construct polite uttcrances. Do you know what tine it is? may be a politc way to ask the time, but Do you know your phone number? is not very politc in most situations, but Could you tell ine your phone number? is.

What is important in this exampic is the exact propositional content of the utterance. People are expected to know phone numbers, but not necessarily what time it is. Using an indirect speech act is not a sufficient condition for politeness. This example illustrates how a social goal can influence what is said. as well as how it is expressed.

Quite often the knowiedge statc goais have been assigned a special priviliged strus among all these goals. Conveying a propsition was viewed as the primary reason for planning an uttcrance, and the task of a language generator was to sumchow construct an utterance that would be appropriate in the current contexL. In contrast, this research attempts to take Halliday's claim [7] seriously in the design of a computer system:

"We do not in fach first decide what we want to say independenty of the setting and then dress it up in a garb that is appropriate to it in the context. ... The 'content' is part of the total planning that lakes place. there is no clear line between the "what' and the "how'. .."

The complexity that arises from the intcractions of these different types of goais leads to simatiuns where the content of an utterance is dictured by the requircment that it fit into the current context. For example, a speaker may plan to inform d hearer of a particular fact. The cuntext of the discourse may make it impossible for the speaker to make an abrupt transition from the current topic to the topic that includes that proposition. To make this transition according to the communicative rules may require planning anuther uttcrance. Planning this uttcrance will in turn gencrate other goals of infurming. concept activation and focusing. The actions used to satisfy these goais may affect the planning of the utterance that gave rise to the subgoal. In this situation, diere is no clear dividing line between "what to say" and "how to say it".

\section{An integrated Approach to Planning Speech Acts}

A probem-solving system that plans utterances must have the ability to describe actions at different levels of abstraction, the ability to specify a partial ordering among sequences of actions, and the ability to consider a plan globally to discover interactions and constraints among the actions already planned. It must have an intelligent method for maintaining alternatives, and cvaluating them cumparatively. Since reasoning about belicf is very important in planning utterances, the planning system must have a knowledge representation that is adcquate for representing facts about belicf. and a deduction system that is capable of using that representation efficiently.
KAMP is a plinning system, which is currendly being implenented. thit builds on the NOAll planning system of Sacerdoti [10]. It uses a possible-worlds semantics upproach to reasoning about belicf and the effects that various actions have on belicf [8] and represents actions in a data structure called a procedural network. The procedural network consists of nixdes representing actions at sumc level of abstraction, along with split nodes, which specify several partually urdered sequences of actions that can be performed in any order, or perhaps even in parallel. and choice nodes which specify aiternate actions, any one of which would achieve the goal.

Figure 1 is an example of a simple procedural network that represents the following plan: The top-level goal is to achicve $P$. The downward link from that node in the net points to an expansion of actions and subgoals, which when performed or achicved will make $P$ true in the resulting worid. The ptan consists of a choice between two alternatives. In the first the agent $\Lambda$ does actions $\Lambda 1$ and $A 2$, and no coinmitment has been made to the ordering of these two parts of the pian. After both of urose parts have been completely planned and executed, then action $A 3$ is performed in the resulting world. The other alternative is for agent $B$ to perform action $A 4$.

It is an important featurc of KAMP that it can represent actions at several levels of abstraction. An INTORM action can be considered as a high level action. which is expanded at a lower level of abstraction into concept activation and fucusing actions. After cach expansion (o) a lower level of abstraction, KAMP invukes a set of procedures called eritics that exatnine the plan glubally, considering the interactions between its parts, resolving confliets. making the best choice among availabie alternatives. and noticing redundant acuons or accions that could be subsumed by minor alterations in anodher part of the plan. Thie contrul structure could be described as a loop that makes a plan, expands it criticizes the result and expands it again, until the entirc plan consists of execulabic actions.

The following is an example of the type of problem that KAMP has been tested on: A robot named Rois and a man named John are in a room that is adjacene to a hailway containing a clock. Both Rob and John are capable of moving, reading clocks, and talking to cach other, and they eact knnw that the other is capable of performing these actions. They both know that they are in the room. and they both know where the haltway is. Neither Rob nur Joln knows what time it is. Suppose that Rob knows that the clock is in the laall, but Juhn does not. Suppose furdher that John wants to know what time it is. and Rub knuws he does. Furthermore, Rub is helpful, and wants to do what he can to insure that John achieves his goal. Rob's planning system inust come up with a plan, perhaps involving actions by huth Rob and John, that will result in John knowing what time it is.

Rob can devise a plan using KAMP that consists of a choice between two alternatives. First if John could find out where the clock is, he could go to the clock and read it and in the resulting state would know the time. So. Rob can tell John where the clock is, asoning that this information is sufficient for John to form and cxecute a plan that would achieve his goal.

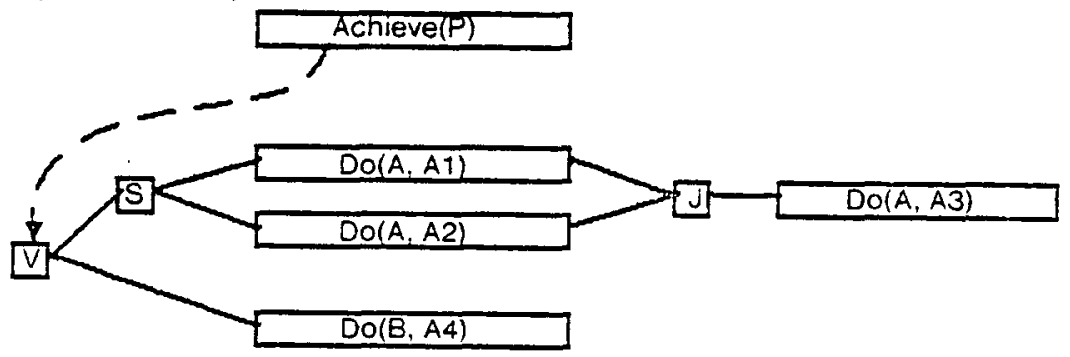

Figure 1

A Simple Procedural Network 


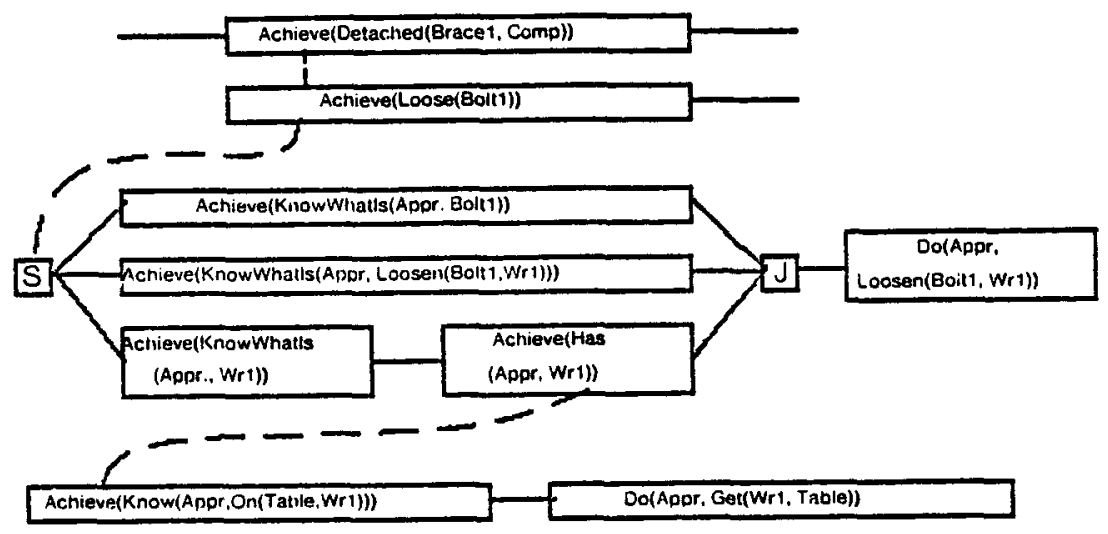

Figure 2

A Plan to Remove a Bolt

The second alternative is for Rob to move into the hall and read the clock himself, move back into the room, and tell John the time.

As of the time of this writing. KAMP has been impicmented and tested on probicms involving the planning of high level speceh act descriptions, and perfonns tasks comparable to the planner implemented by Cohen. $\wedge$ more complete description of this planner, and the motivation for its design can be found in [1]. The following example is intended to give the reader a fecling for how the ptanner will procecd in a typical situation involving linguistic planning, but is not a description of a currently working system.

An expert and an apprentice are coopcrating in the task of repairing an air compressor. The expert is assumed to be a computer system that has complete knowledge of all aspects of the task, but has no means of manipulating the world except by requesting the apprentice to do things and furnishing him or her with the knowiedge needed to complete the task.

Figure 2 shows a partially completed procedural network. The node at the highest level indicates the planner's top-level goal, which in this case is removing a particular object (BRACEI) from an air compressor. It knows that this goal can be achieved by the apprentice executing a particular unfastening operation involving a specific wrench and a specific bolt. The expert knows that the apprentice can do the action if he knows what the objects involved in the task are, and knuws what the action is (i.e. that he knows how to do the action). This is reflected in the second gual in the split path in the procedural network. Since une pian also requires obtaining a wrench and using it a goal is also established that the apprentice knows where the wrench is: hence the goal ACIIIEVE(Knuw(Apprentice. On(Table, Wri))).
Assume that the apprentice knows that the part is to be remured, and wants to do the removal, but does not know of a procedure for doing it. This situation would hold if the goal marked with an asterisk in figure 2 were unsatisficd. The expert must plan an action to inform the apprentice of what the desired action is. This gual expands into an INFOrM action. The expert also believes that the apprentice does not know where the wrench is, and plans another INI:ORM action to tell him where it is located.

The ptanner tests die ACminte guals to see if it believes that any of them are already true in the current state of the world. In the case we are considering. KAMP's model of the hearer should indicate that he knows what the bolt is. and what the wrench is, but doesn't know what the action is. i.e. that he should use that particular wrench to loosen that bolth and he doesn't know the location of the wrench. If informing actions are planned to satisfy those goals that are not already satisfied, then that part of the plan looks like Figure 3.

Each of the INFORM actions is a high-level action that can be expanded. The planner has a set of standard expansions for actions of this type. In NOAll, these actions were written in Soup code. In this planner, they are represented in situation-action rules. The conditional of the rule involves tests on the type of action to be performed. the hearer's knowledge, and social goals. The action is to setect a particular strategy for expanding the action. In this case, a rule such as If you are expanding an inform of what an action involving the hearer as agent is then use an IMPERATIVE syntactic construct to describe the action. The planner then insers the expansion shown in Figure 4 into the plan.

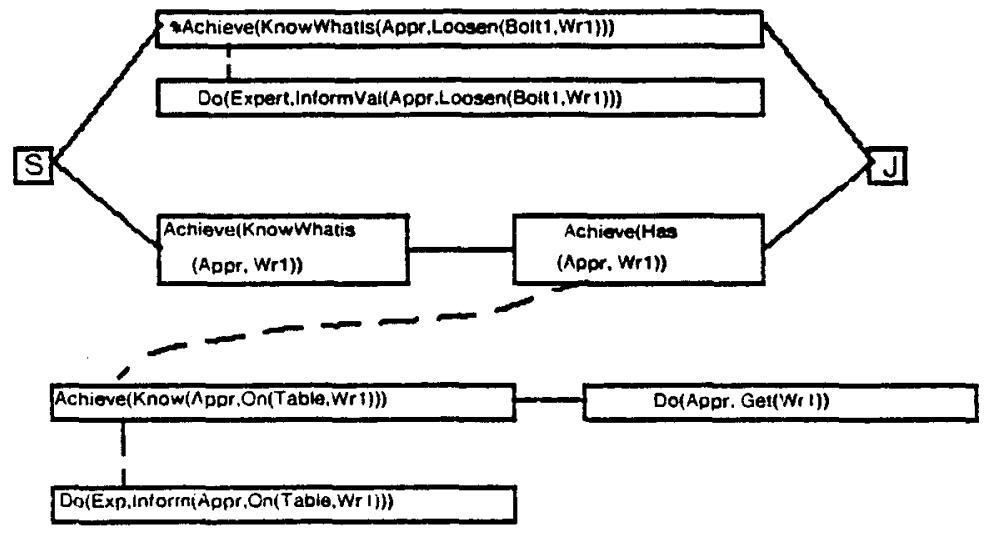

Figure 3

Planning to Inform 


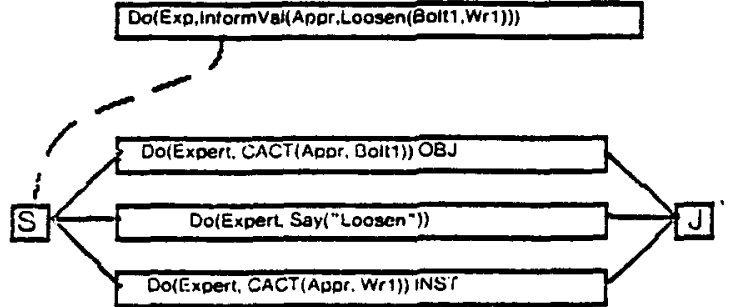

Figure 4

Expanding the INFORM Act

This sub-pian is marked by a tag indicating that it is to be realized by an inperative. The split specifies which lower level actions are performed by the utterance of the imperative. At some point. a critic will choose an ordering for the actions. Wittout further information the senicnec could be realized in any of the following ways, some of which sound strange when spoken in islolation:

\section{Loosen Boltl with Wrl. With Wrl loosen Boltl. Boltl lousen with Wr1.}

The first sentence above sounds natural in isolation. The other two might be chusen if a critic nutices a need to realize a focusing action that has been planned. For example, the second sentence shifts the focus to the wrench instead of the bolt, and would be useful in organizing a series of instructions around what tools to use. The third would be used in a discourse organized around what object to manipulate sext

Up to this poimt. the planning prucess ins been quite straigheforward, since none of the erities have come into piay. However, sinee there are two INFORM actions on two branches of the same split, the COMBINE-CONCEPTActivartion eritic is invoked. This critic is invoked whenever a plan contains a concept activation on onc branch of the split, and an inform of some property of the activated object on the other branch. Sometimes the planner can cumbine the two informing actions in $w$ one by including the property description of one of the informing acts into the description that is being used for the concept activation.

In this particular example, the eritic would atheh to the DorExper CACT(Appr.. Wr1)) action the coitstraint that one of the realizing descriptors must be $O N(W r 1$. Table), and the goal that the apprentice knows the wrench is on the table is marked as already sacisfied.

Another critic, the REDUNDANT-PATH critic, notices when portions of two brances of a split contain identicai actions, and collapses the two branches into one. This critic, when applied to utcerance plans will oflen result in a sentence with an and conjunction. The critic is not restricted to apply only w linguistic actions, and may apply to uther types of actions as well.

Other critics know about action subsumption, and what kinds of focusing actions can be realized in terms of which linguistic choices. One of these action subsumption critucs can make a decision about the ordering of the concept activations, and can mark discourse goals as pha.. mns. In $t$ is example, there are no specific discourse goals, so it is pussible to chose the dcfault verb-objectinstrument ordering.

On the next next expansion cycle, the concept activations must be expanded into uttcrances. This means planning descriptors for the objects. Planning the right description requires reasoning about what the hearer believes about the objech describing it as eionomucally as possible, and then adding the additional descriptors recommended by the action subsumption critic. The final step is realizing the descriptors in natural language. Some descriptors have straightforward realizations as lexical items. Others may require planning a prepositional phrase or a relative ciause.

\section{Formally defining litiguistic actions}

If actions are to be planned by a planning system. they must be defined formally so they can be used by the system. This means explicitly stating the preconditions and effects of each action. Physieal actions have received atcention in the literature on planning, but une aspect of physical actions that has been ignored are their effeets on knowledge. Moore [8] suggests an approach to formalizing the knowiedge effects of physical actions. so I will not pursue that further at this eme.

A fairiy large amount of work has been done on the formal specification of speceh acts un the level of informing and requesting, etc. Most of this work has been done by Searic $[11]$, and has been incorporated into a plisnning system by Cohen [3].

Not much has been done to formally specify the actions of focusing and concept activation. Sidner [12] has developed a set of formal rules for detecting focus movement in a discourse, and has suggested that these rules could be translated into an appropriate set of actions that a generation system could use. Since there are a number of well defined strategies that speakers use $w$ focus on different topics. I suggest that the preconditions and effects of these strategies could be defined precisely and they can be incorporased as operators in a planning system. Reichmann [9] describes a number of focusing stratcgies and the situations in which they are applicable. The focusing mechanism is driven by the speaker's goal that the hearer know what is currently being focused an This particular type of knowledge state goal is satisfied by a varicty of different actions. These aetions have preconditions which depend on what the current state of the discourse is. and what type of shift is taking place.

Consider the problem of moving the focus back to the previous topic of discussion after a brief digression onto a different but related topic. Reichmann points out that several actions arc available. Onc such action is the utterance of "anyway" which signals a mure or less expected focus stiit. She claims that the utternnce of "but" can achieve d similar effect. but is used where the speaker believes that the hearer helicves that a discussion un the current topic will continuc, and that presupposition needs to be countered. Each of these two actions will be defined in the planning system as operators. The "but" uperator will have as an additional precondition that the hearer believes that the speaker's next utterance will be part of the current context. Both operators will have the effect that the hearer believes that the speaker is focusing on the previous topic of discussion.

Other operators that are available include explicity labeled shifts. This operator exp. ids into planning an INFORM of a focus shift. The previous example of Take John for insiance is an example of such an action.

The precise logical axiomitization of focusing and the precisc definitions of each of these actions is a topic of curre..t research. The poill being made here is that these focusing actions can be specified formally. One goal of this research is to formally describe linguistic actions and other knowledge producing actions adequately enough to demonstrate the feasibility of a language planning system.

\section{v. Current Status}

The KAMP planner described in this paper is in the carly stages of implemencation. It can solve inceresting probiems in finding multiple agent plans. and plans involving acquiring and using knowlege. It has not bcen applied directly to language yec but this is the next step in research. 
Focusing actions need to be described formally, and critics have to be defined precisely and implemented. This work is currently in progress.

Nlthough still in its carly stages, this approach shows a great deal of promise for developing a computer system that is capable of producing utcrances that approach the richness that is apparent in even the simplest human communication.

\section{REFERENCES}

[1] Appelt, Duuglas, A Planner for Reasoning about Knowledge and Belief, Procecdings of the First Conference of the American Assuciation for Artificial Incelligence, 1980.

[2] Austin, J., How to Do Things with Words, J. O. Urmson (ed.), Oxford University Press. 1962

[3] Cohen, Philip, On Knowing What to Say: Planning Spech Acts, Technical Report \#118. University of Toronto. 1978

[4] Gricc. H. P., Logic and Coversation, in Davidson, ed., The Logic of Granmar, Dickenson Publishing Co., Encino, California, 1975.

[5] Grosz, Barbara J., Focusing and Description in Nalural Language Dialogs, in Elements of Discourse Understanding: Proccedings of a Workshop on Computational Aspects of Linguistic Structure and Discourse Setting, ^. K. Joshi et al. eds., Camuridge University Press, Cambridge. England. 1980.

[6] Halliday, M. A. K., Language Structure and Language Function in Lyons, ed. New Horizons in Linguistics.

[7] Halliday, M. A. K., Language as Soxial Semiotic. University Park Piess, Baltimore, Md., 1978.

[8] Moore. Robert C., Reasoning about Knowledge and Action Ph.D. thesis, Massachuscts Institute of Technology, 1979

[9] Reichman. Rachel. Conversational Coherency, Center for Research in Computing Technology Technical Report TR-17-78. Harvard University, 1978.

[10] Sacerdoti. Eart, $\wedge$ Structure for Plans and Behavior, Elsevier NorthHolland. Inc., Amsterdam. The Netheriands, 1977

[11] Searle, John, Speech Acts. Cambridge Universiy Press, 1969

[12] Sidner, Candace L. Toward a Compulational Theory of Definite Anaphora Comprehersion in English Discourse. Massichusetts Institutc of Technology Aritificial Intelligence Laboratory technical note TR-537, 1979. 


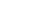

